\title{
Hyperinsulinism due to HNF4A deficiency
}

INSERM

\section{Source}

INSERM. (1999). Orphanet: an online rare disease and orphan drug data base.

Hyperinsulinism due to HNF4A deficiency. ORPHA:263455

Hyperinsulinism due to HNF4A deficiency is a form of diazoxide-sensitive diffuse hyperinsulinism (DHI), characterized by macrosomia, transient or persistent hyperinsulinemic hypoglycemia $(\mathrm{HH})$, responsiveness to diazoxide and a propensity to develop maturity-onset diabetes of the young subtype 1 (MODY-1; see this term). 